\title{
Marital Suffering and the Assisted Reproductive Technology Process: The Case of an Infertile African Spouse
}

\author{
Marguerite Rose Nguekeu*, Leonard Nguimfack\#, Jacques-Phillipe Tsala Tsala\# \\ Psychopathology and Clinic Laboratory, Department of Psychology, University of Yaoundé 1, Yaoundé, Cameroun \\ Email: *marguyrose@gmail.com
}

How to cite this paper: Nguekeu, M. R., Nguimfack, L., \& Tsala, J.-P. T. (2022). Marital Suffering and the Assisted Reproductive Technology Process: The Case of an Infertile African Spouse. Psychology, 12, 101-118. https://doi.org/10.4236/psych.2022.131008

Received: November 20, 2021

Accepted: January 25, 2022

Published: January 28, 2022

Copyright $\odot 2022$ by author(s) and Scientific Research Publishing Inc. This work is licensed under the Creative Commons Attribution International License (CC BY 4.0).

http://creativecommons.org/licenses/by/4.0/

\begin{abstract}
This work deals with the Assisted Reproductive Technology (ART) process, of an infertile spouse who faces a proposal for Artificial Insemination with Donor (AID), in a cultural context where male infertility is still taboo and where this practice is not yet really anchored in manners. Indeed, research in clinical psychology does not sufficiently consider this aspect of the suffering in the couple. However, according to ethno-psychiatric theory, the therapeutic route of the African patient depends largely on cultural representations of his disease. This work aims to study the repercussions of the suffering of an infertile African spouse on his ART/AID process. This research was conducted with three infertile men ranging in age from 37 to 44; after experiencing the failure of the first ART attempt, they were called upon to undergo an AID protocol. Data were collected using semi-structured individual research interviews and the Hospital Anxiety and Depression scale (HADs). These data were analyzed using content analysis technique. Thus, the suffering of the infertile spouse at this level can be justified by cultural constraints, the shame of the social gaze, the secrecy maintained by the culture on this practice. Sometimes, this spouse perceives his infertility as the consequence of villain-induced mystical persecution; which generates tensions between him and his spouse, his family and those close to him. Under the cultural pressure that demands a blood child, this ART/AID process is camouflaged by shame, doubt about the quality of the unborn child and even about the competence of the medical workers. The positive diagnosis of anxio-depressive syndrome in the participants after analysis of the HADs scores would also be justified by the absence of psychological care in the ART/AID process.
\end{abstract}




\section{Keywords}

ART/AID, Ancestral Values, Infertility, Marital Suffering

\section{Introduction}

Researchers from different fields of human and social sciences have discussed at length through their pens, the issue of new reproductive technologies (artificial insemination with donor sperm) in the world, and even in Africa. The psychoanalyst Delaisi de Parseval (2009), for having worked on the question of father, IAD in order to deepen the psychodynamics of the sterile man who becomes a father through another via the IAD, will affirm that the concept "father" can apply to several figures or designate various characters. Anthropologist Bonnet (2014) who has researched PMA in Cameroon; explains that the life stories of a couple facing the medical journey highlight a feeling of physical and moral exhaustion among the partners. For Théry \& Leroyer (2014), sociologist and lawyer respectively, propose three components in the identification of the parent; namely: the biological, domestic and genealogical components. First, make the parent the genitor, the second identifies the one who brings up the child on a daily basis and at the level of the third, it is the law that designates the parent. The clinical psychopathologist Durif-Varembont and the psychiatrist Rosenblum in 2018 (DurifVarembont et al., 2018), underline that the ADI brings into play a family dynamic beyond that of the couple confronted with the severe infertility of the man. Reproductive biologist Jouannet (2013), about artificial insemination with donor sperm will ask questions: first, does not the man who has had recourse to the sperm of a donor run the risk of seeing weaken the quality and the solidity of the bonds which will unite him to his child? Then, do the family circle and society place as many values on this fatherhood as on natural one? And finally, he wonders: if the child was not conceived with his own sperm, his father's own genes, is he going to look like him? According to Squires et al. (2008) and Kaufman (2014), the process of becoming a medically assisted procreation parent is long, painful due to the wait and even disappointments.

This work, therefore, involves understanding how the suffering of an infertile Cameroonian spouse, culturally apprehended, disrupts his or her MAP journey.

To initiate the central concern of this research, we will insist on the place of the child in Africa; the shame; even the taboo aspect of male infertility; the momentum of the victim in a therapeutic multiverse; the gaze that African society is about the practice of this new technology; with an emphasis on artificial insemination with donor sperm (IAD); and finally the related cultural constraints which make this course a real "obstacle course".

\subsection{The Place of the Child in Africa}

Africa is an essentially vitalist continent (Tabong \& Adongo, 2013); thus, child- 
bearing is highly valued in the African community and Childlessness is highly stigmatised in this community with manifold social consequences. This is why the place given to the child is essential in a couple (Nguekeu, 2015). Moreover, the primary goal of marriage is fertility and by extension, the enlargement of the community. Childlessness involves conflict and marital suffering in the spouses. The child has thus become the central pillar of marital stability. Researchers such as Sow (1977, 1978), Yana (1988) and Hurault (1987) are interested in the value placed on the child in the African couple. According to these opinions, we did not really die in Africa when we left offspring; this gesture testifies to the transmission of the individual history of the progenitor, the fulfillment of his oedipal desires and the perpetuation of his ancestral cultural values. Likewise, fertility appears to be a means of self-assertion in African society. This is what makes the strength of several chiefs and kings in the western region of Cameroon. Aoudou (2009) already pointed out that the family organization in most African societies in general and Cameroonian in particular values people who have many children; which motivates men to win more children. The status of a man is valued by his ability to procreate (Meijers, 2020). This is how giving life is the most important act for the perpetuation of cultural values. Likewise, fertility is a sign of blessing, birth a marvelous event which is accompanied by feast in some tribes. The birth of a child in an African family is the joy of the whole community, which shows its gratitude to God and/or to the guardian deities of the family.

\subsection{The Shame and Taboo of Male Infertility}

Couple's infertility is considered inevitable in Africa. It is also the leading cause of marital and even family disagreements, especially when it is of female origin. The male origin of infertility is recently discovered; formerly only the woman was blamed in the infertility of the couple (Tiu et al., 2018). Yet male infertility is the cause of more than a third of infertility in couples. It is explained by a quantitative and or qualitative alteration of the sperm, of congenital or acquired origin. According to the WHO (2010) infertility is of male origin in $20 \%$ of cases, of female origin in $30 \%$ of cases and of mixed origin in $40 \%$ of cases and no cause is found in $10 \%$ of cases. When infertility is of male origin, the affected person feels devalued because they are unable to prove their virility. Taking the example of the Beti of Cameroon Aoudou (2009), emphasizes that the unfortunate person is so overcome with anguish, especially when he wonders about the message he will send to the college of ancestors and the fate that will be reserved for him. His situation appears to be a disruption of the balance of the vital order, especially since he is in failure of loyalty (Boszormenyi-Nagy \& Spark, 1973), to his couple, to his family and even to his community. One can also evoke in the man with childishness a kind of loss of self-esteem which is accompanied by a feeling of incompleteness due to his inability to fulfill his duties as a father. Also, by birth, he contracted a debt of life which he will repay only 
by giving birth in turn to an offspring to perpetuate the lineage. Male infertility is as much taboo as it is not alluded to, due to the shame that accompanies it. To come to the end of his tribulations carrying curse in his marriage, the baby hunter will throw himself into a therapeutic multiverse.

\subsection{The Momentum towards a Therapeutic Multiverse}

This is about traditional, religious and biomedical therapies. The problem of infertility does not leave the couple indifferent. The members of the couple concerned will resort to a therapeutic multiverse in no specific order. It all depends on who first proposes a remedy. It should be noted that such a situation does not go unnoticed regardless of ethnicity in Cameroon. In the Sawa group, for example, to deal with infertility as a couple, they practice the "Esa" rite. This rite is a moment of questioning which can only be invoked in the event of a serious crisis in the family unit, in the clan, in the entire tribe, or even on an even larger social scale. The rite of Esa ya mboa is called in cases of infertility to seek help from the Sawa deities to alleviate the pain of the victim.

In western Cameroon, it is rather essential to maintain the skulls of ancestors at the risk of falling victim to the wrath of spirits; which could cause infertility and many other curses. In addition to respecting the skulls of ancestors on which sacrifices will have to be made to attract happiness to the lineage, infertility is due to disobedience to ritual practices, transgression of prohibitions and witchcraft. These peoples make sacred groves (sacred forests) the privileged places for rituals, in the event of proven suffering of a member of the tribe. When the practice of rites in the case of male infertility seems unsuccessful in this tribe, the in-laws arrange for the woman to meet one of her husband's brothers (Ngon, 2018), this in the strict family privacy; once conceived, the latter returns to her partner in an effort to keep not only her honor but to ensure her lineage. It should be noted that the observation of rites and rituals is frequent, especially in the face of couples' infertility problems in Africa. According to Faye (2011), traditional therapists are sought after by patients not only because of their dynamism and omnipresence, but also because of the popular imagination which has favored them and the uniqueness of their professionalism.

With regard to religious therapy, it should be noted that infertility causes often very significant emotional difficulties in victims, thus creating isolation accompanied by narcissistic injury. This is how the unfortunate ones start prayer sessions, because they experience a kind of guilt. Their testimony states that the Bible shows that God gives life, fertility: "I will make you extremely fruitful, out of you I will make nations, and kings will come out of you" promise made to Abraham (Genesis 16, 6). This native filial condition not only cultivates lineage reference but generates a kind of guilt in the infertile person who finds himself marginalized from it. It must be said that in the Old Testament, sterility was denounced as a lack, a great suffering and a shame; this is experienced as a breach of the injunction of God who says: "Be fruitful, multiply" (Genesis 1:22). 
And further on in the Book of Wisdom $(3,13)$ it is written: "Happy is the barren but spotless woman! Its fruitfulness will appear during the visit of souls". Faced with the destabilizing situation of infertility, the victims immerse themselves in prayers, days of fasting and novena to ask for repentance from God in order to benefit from this gift of procreation. Moreover, it is frequent these days to meet people who, faced with their situation of infertility, devote themselves to praise and adoration in the hope of blocking the road to mystico religious persecutions and of being rewarded like Sarah in the bible, or Zakaria in the Koran.

As for biomedical therapy, assisted reproductive technologies remain the ultimate route (Boden, 2013) when all others are exhausted to no avail. Although the ART offers patients the hope that they may have offspring, however, neither does it pass without criticism.

\subsection{Social Perspective and ART}

The assisted reproductive technologies especially the AID are rather mystified in some African societies. This highlights the secret in practice, the shame of the gaze thus generating multifaceted suffering for the applicant, especially since the child who will be born there is rather the child of the couple and not the child of the lineage (Bonnet \& Duchesne, 2016), these authors emphasize that it is not only a question of having children, but rather of making parents. In this case everything is going under a secret. The fact of maintaining the secrecy of the AID in the couple can make life hellish for these recipient couples. These authors think that the choice of the absolute unsaid leaves the couple alone without the possibility of sharing his sufferings, his anxieties and his doubts. This could be the result of a lack of confidence in an outside world deemed hostile or unreliable. Partners will prefer silence, withdrawal and avoid subjects of comments and remarks that could be hurtful or ironic.

\subsection{Cultural Constraints and Difficulty in the AID Process}

Artificial insemination with donor (AID), first used in clinical practice in England in the late 1930s (Frith, 2001), is a technique of medically assisted procreation, set up to alleviate male infertility in couples. This technique, much appreciated in the West for its prowess, does not seem to suit all Africans because of several socio-cultural factors. This causes marital suffering in some infertile couples engaged in the process of medically assisted procreation. The African gives more consideration to the transmission of blood. This explains the practice of fosterage as presented by Bonnet (2014). It is about the fact for an infertile couple to take a child in his kinship to fill the childishness which plagues their couple, while waiting for the Lord to grant them the donation of a biological child. It must be said that the blood tie brings together the traits of resemblance, the sharing of certain habits and certain practices/customs in the near or distant family. Submitting to an AID would therefore be considered sacrilege, aberrant 
conduct, betrayal within this cloister strengthened by an ancestor (protector of the group), brings good luck to his umbilical descent (Howe et al., 2020). The practice of AID creates a sort of break with socio-cultural bodies as defined by Sow $(1977,1978)$. This author shows that the psychic universe of the African is governed by three hierarchical sub-universes namely: the macrocosmos which is a sub-universe composed of God and the ancestors, the mesocosmos which is the sub-universe composed of evil spirits and sorcerers and the microcosmos, made up of visible and palpable physical elements as well as the biolignage.

Moreover, the process of ART/AID in some Africans is littered with a panoply of pitfalls, with serious consequences on the psychological aspect of the applicant (marital and intrapsychic suffering), which, it would be detrimental not to do an exploratory study.

\section{Methods}

The research described in this article was carried out by the author Marguerite Rose Nguekeu, as part of the writing of her doctoral thesis. This has been done between August and December 2019.

\subsection{Participants}

The data was collected from three infertile men ranging in age from 37 to 44 . The small number of participants is explained by the fact that in Africa, men are not very present in fertility centers. And in this case, our inclusion criteria were very strict. It was not only necessary to select the men who come for the second time, (which is not very common) but those who, after having experienced the failure of the first ART attempt were called upon to submit to a protocol, IAD due to the poor quality of their sperm. These participants were selected by the reasoned choice sampling method (which is this non-probability sampling procedure, which consists in selecting participants considered to be typical of the target population) during the consultation in a fertility clinic in the region, City of Douala in Cameroon.

\subsubsection{Inclusion Criteria}

- Have spent more than a year living as a couple under one roof; WHO (2010) defines infertility as the absence of pregnancy after more than 12 months of regular intercourse without contraception;

- Present an infertility problem formally established by obstetric examinations;

- Be in a fertility center;

- Be on his second AMP attempt;

- Have given the favorable opinion on the informed consent form.

\subsubsection{Exclusion Criteria}

Any couple who did not meet the above inclusion criteria was excluded from the scope of this research. However, according to the information notice, any participant was free to withdraw from the research at any time. Also, any man who 
cannot produce sperm, as the case of azoospermia, is excluded from the scope of this research.

\subsection{Semi-Structured Interviews}

The semi-structured research interviews were conducted consecutively with the HADS graduation. These tools seemed effective in understanding the psychic functioning of these participants. The semi-directive research interview, thanks to its semi-directive property, made it possible to explore more or less specific aspects of the psychic functioning of the participants in relation to the research objectives. A total of six interviews were conducted, two per case, with an average duration of 45 minutes each. After the first interviews, the participant's consent was requested for any telephone interviews, given his availability.

\subsection{The Graduation of HADs}

They were conducted individually during gyneco-obstetrics follow-up consultations, during which the infertile partner took a few minutes to complete a standardized self-assessment questionnaire. This is the Hospital Anxiety Depression Scale (HADs) also known as the Hospital Anxiety Depression Scale (HADs). In its current use, this scale is made to diagnose anxio-depressive syndrome in patients.

\subsection{Data Analysis}

For data analysis, content analysis in its formal variant was used since it is fundamentally qualitative and considers the analysis of expressions, utterance, co-occurrences and forms of discourse.

\section{Results}

\subsection{Results of HADS}

After taking the HADs scale, Mr. A. expected a score of 13 on the Anxiety sub-scale and 11 on the depression sub-scale. As for Mr. C, he scores 10 on anxiety and 13 on depression. With regard to Mr. F, he also discounts 10 on the anxiety subscale and 12 on the depression level.

\subsection{Results of Semi-Structured Interviews}

Results of semi-structured interviews are presented in tables for better visualization. During the analysis of the different discourses, since it is the thematic content analysis, the recurring expressions were identified and this is what made it possible to design these tables. It should be remembered that these are the open-ended interviews where we used an interview guide. Table 1 shows the anamnestic data of Mr. A (a pseudonym assigned for confidentiality reasons). The three columns present, respectively, the themes, the descriptors that were recurrent among the participants but the verbatim clearly show the bottom of their thoughts. Table 2 and Table 3 respectively highlight the data of Mr. C and 
Table 1. Presentation of anamnestic data and results of the interview with Mr A.

Mr. A is 37 years old. Originally from the region of Equatorial Guinea, of Fan ethnicity. He is an administrative agent by profession. Lived as a couple for years. Failed Insemination in 2017. Despite financial difficulties, the couple returned in 2019 for a second attempt. Suffers from trace asthenospermia. Second born of a sibling of 9. Mr. A., admits having been with a pastor who had unsuccessful prayer sessions, he consumed traditional potions in vain and is worried about this "bad luck" of which he is a victim. Determined to continue this process to the point of success. But it turns out that his problem is worse than he thought. The doctor offers him an Artificial Insemination with sperm from the Donor; there is no answer.

\begin{tabular}{|c|c|c|}
\hline Themes & Descriptors & Verbatims \\
\hline \multirow[t]{3}{*}{$\begin{array}{l}\text { Data related to } \\
\text { cultural } \\
\text { constraints }\end{array}$} & $\begin{array}{l}\text { Pressure from family and } \\
\text { loved ones to continue the } \\
\text { lineage }\end{array}$ & $\begin{array}{l}\text { "It's very hard for me but what should I do?"; "Is that when you stay you are only } \\
\text { asked what you are waiting for to have your part of a child"; "My mother must see } \\
\text { my part of a child before she dies, she is in a lot of pain as she sees me like this." }\end{array}$ \\
\hline & $\begin{array}{l}\text { Respect for ancestral } \\
\text { values, safeguarding the } \\
\text { spiritual and social } \\
\text { heritage }\end{array}$ & $\begin{array}{l}\text { "We also want to have children like everyone else; but we seek, we seek, nothing } \\
{[\ldots] \text { "; "Hey doctor, the child is the future, isn' t it? This is our [...] Change, isn' tit? }} \\
\text { of our life but normally children are not just for us [...], it's God"s gift, right? that } \\
\text { he gives to everyone." }\end{array}$ \\
\hline & $\begin{array}{l}\text { The practice of spiritual } \\
\text { rites and traditional } \\
\text { rituals }\end{array}$ & $\begin{array}{l}\text { "The pastor made a lot of liberation with prayer but [...]"; "My mother sometimes } \\
\text { brought us traditional medicines that we drank"; "She said it's to wash the } \\
\text { stomach"; "People are the custom with us, with problems like that"; "When you go } \\
\text { to the hospital, it doesn't work, you also try at the marabouts." }\end{array}$ \\
\hline \multirow[t]{3}{*}{$\begin{array}{l}\text { Data related to } \\
\text { the secret of the } \\
\text { AID }\end{array}$} & The secrecy's weight & $\begin{array}{l}\text { "We only do things together, we hide by what we only think we are going to have } \\
\text { our own child"; "You can't tell someone"; "it is not easy"; "The last time it failed we } \\
\text { didn't tell people, we kept it a secret." }\end{array}$ \\
\hline & $\begin{array}{l}\text { Failure of loyalty to } \\
\text { spouse, family and } \\
\text { community }\end{array}$ & $\begin{array}{l}\text { "You don't have a child; how do you live? people look at you badly". "When your } \\
\text { age is already passing your parents start to ask you what are you waiting for to be } \\
\text { child. My father asks me if } \mathrm{m} \text { going to stay like some white people"; "I come from } \\
\text { a polygamous family, it is I alone who do not have the children yet and we do not } \\
\text { know why"; "Everyone complains." }\end{array}$ \\
\hline & $\begin{array}{l}\text { The personal } \\
\text { representation of } \\
\text { ART/AID }\end{array}$ & $\begin{array}{l}\text { "But it s the suffering, we take the remedies, we come, we go, it s all money, isn't it? } \\
\text { "But how are we going to do, I myself am in pain, you see that walking to the } \\
\text { hospital all the time, all the time like that is not easy, and the child does not come?"; } \\
\text { "As for the IAD, you know the women you can do that, one day when there are } \\
\text { problems, she says to everyone, how am I going to do? If I can even accept that, the } \\
\text { doctor must not tell him [...], if people know what kind of father will I be, what am } \\
\text { I going to tell my family?" }\end{array}$ \\
\hline
\end{tabular}

Data related to The feeling of guilt the shame of the social gaze
"When she had the miscarriage she lost a lot of blood, I was too scared"; "I was overwhelmed, I was asking God what I did to make it like this, what did I do to make this happen to me? I think too much, I can't sleep, I see how she is in pain like this, it bothers me a lot."

The feeling of loss of "I can't do anything else", "This is the time of suffering, I felt very bad especially self-esteem and the fear of when the doctor told me that my problem was serious, I couldn't say anything in a possible divorce front of her"; "I cannot tell them that I too have the problems and that I am in great pain"; "But in my case worries me a lot", "she may leave me one day."

The feeling of incompleteness
"The doctor explained to me that my semen is a little weak. that it's not very good; I
don't know what made it weak", "ah, he's going to see if that's the thing that's
dead"; "We take the children of our family, you understand a little, don't you? But
you know that the family is a bit difficult in our custom"; "Currently we have eleven
children in our house. But when there is the problem, we are insulted." 


\section{Continued}

Data related to The relationship to "I do not understand; or it's bad luck or bad people did this I don't know." mystical-religious witchcraft practices

Beliefs in evil spirits and supernatural powers
"We tried, but at home, we sometimes say that bad people do that too, that you can't give birth"; "We drank but it didn't work"; "We turn this over to God, we know that it is he who gives the children. If it s the sorcerer, God will help us someday."

"This is the second time... we first did the other in 2015. It didn't work out, we were still looking for the money to do the other." "We came here, we did the infiltration, we went home, but the first month it went well we went to our clinic over there in our country to do the ultrasound. was we, but the third month, it came out", "we cried our child so much there..."

Doubt about the quality of "The other than the doctor says you can take someone's semen there is the unborn child via AID complicated"; "P m going to think again, it's even what a curse on me like that."

Doubt about therapeutic "Eeh, ah, we are there too, what we are asked to do, we also do, we pray to God that efficacy for us also succeeds, but we spend too much. we just want them to do it just be good, so that we live as well as the others, if it works so much the better"; "Her friend who explained to her that people do that, and that when you' re lucky, it works"; "But if for me it works, one day I can also tell someone, what will also do to see."

Table 2. Presentation of anamnestic data and results of the interview with Mr. C.

Mr. C, originally from the western region. Bamileke ethnicity. 44 years old. Trader in the city of Douala. Lack of mobility, vitality and insufficient quantity of sperm in semen. Catholic religion. Last of five siblings. Only child of his mother who has not yet procreated. 7 years of married life, and therefore 11 years of perpetual child search. From the age of 30, her first marriage. Second marriage at 33. Engaged in his third union practically at the age of 37, he and his wife throw themselves into traditional decoctions of all kinds without convincing results. He therefore takes the initiative to get help from the PMA; What was done with failure, after a month of pregnancy. After the recent spermogram, the doctor offered her an IAD because her examinations revealed severe asthenospermia.

Themes Descriptors Verbatims

Data related to

cultural constraints
Pressure from family and loved ones to continue the lineage

Respect for ancestral values, safeguarding the spiritual and social heritage

The practice of spiritual rites and traditional rituals
"We certainly have the pressure of the family, well [...] but, the house is not completely empty, we have the children of the family good, at least that allows them to take it. But everyone would like us to have for ourselves."; "It is true the look is a little strange but we live like that". "... I come from an area where man lives to prepare for his death. It is one of the elements that allow you to mark your passage on earth, which allows you to be remembered."

"I grew up in this culture where the child is the center of everything, the beginning and the end of everything"; I told you that in our Bamileke customs, we only live for children, we live by preparing for death, and it is the child who will replace you when you are not there. Your brother's child is not your child'; if the ancestors gave too much importance to the child and our parents did too, why am I going to stay without following the chain."

“...But I took a lot of so-called natural products, that is to say the decoctions made from the bark of trees, herbs, things,..." "we even tried to think of the ceremonies, the rites that it had to be done in the village"; "The rare times my mom came to my house, it was to give the remedies she takes from traditional healers"; "She was chatting that the custom has been neglected and these are the consequences" "she would ask that I be washed traditionally to cleanse me from the curse or certain sins that my ancestors committed in their day and which follow you." 


\section{Continued}

Data related to the secret of the AID
The secrecy's weight

Failure of loyalty to spouse, family and community

The personal representation of ART/AID
"Stuff like that can only be shared with your wife, since we started this, no one knows, even when the pregnancy broke last time there, her mother knew she had conceived normally."

"I also have a lot of siblings. To my mom I am the last born, and none of my elders so far has had such a history, even in the big family. This is really my bad luck for me"; "When it's like that you can't be quiet like everyone else; this is a situation that is for you alone and bothers you; it even creates problems in your life, you don't know what to say to people, or even to your wife."

"I have sufficiently immersed myself in the practices of medicine"; "I always remained confident despite it being really, really hard to bear", everything I did as an exam with the urologists, the gynecologists...so all that had to be done on me for an exam until today' hui has never been able to understand why I am having these problems. "I took food supplements, vitamins... no positive results"; "If it weren't for the financial means, I would have started AMP a little earlier."
Data related to The feeling of guilt the shame of the social gaze
"But when I see all the suffering in the hospital, really, I don't sleep well."; "Since it was I who was consoling madam, I told her that it was nothing, that it was only the first try and that in any case we had very little chance that it would be a success"; "My real fear is at the level of dying without leaving a child, what will I say to my ancestors? after my death? I will not have left any trace on earth. This is especially my real problem."; "It is I alone among the children of my mother who suffers like that."

The feeling of loss of "I can only have this urge, that is, there is this urge that is strong and after age is self-esteem and the fear of passing, at one point perhaps we will even risk not having the strength to raise them a possible divorce or even to do it completely"; "I no longer have the same initial motivation"; "P ve been told about vitality, uhhh, mobility, sperm (tone drops), the amount of sperm is insufficient (the sentence is difficult to grasp); "I thought to myself that the problem would be deeper than that?" "I told myself that I was going to overcome but it was after that I started to get depressed, because I have already lost two marriages always for that."

The feeling of incompleteness

"I told you that having a child is at the center of my concern now, and the results are not positive [...], well I will always try"; "and I also do not want to die childless"; "Taking the child of your brothers does not solve the problem"; "It's very hard to be childless, you yourself feel an emptiness in you"; "no one will talk about you."

Data related to The relationship to mystical-religious witchcraft practices

Beliefs in evil spirits and supernatural powers
"Maybe someone is attacking me mystically, this case is beyond me"; "If there are also wizards in the family, they are said to tie up or block people's chances."

"I mean we tried to think about supernatural things"; "we said it's because we did this or we don' thave that that the curse catches people, hey uhhhh, I don't know what 'they did in their time so that this curse follows us like this."

"So uhhh, I was still confident even though it was really, really hard to take, yes it's really hard. [...] this is a situation where you had to go through a lot of stages and.... Well, we are only in this process and we will have to go step by step to finally get a good result."

Doubt about the quality “...that's even what $1 \mathrm{~m}$ afraid of and it bothers me a lot. You know your very of the unborn child via AID brother's child, you know it's your blood, but what you take in the hospital, you don't know what you take to bring home." 
Doubt about therapeutic "This is what I want to know since. Hmmmmm, I m overwhelmed, that's what I efficacy really want to know, if the doctors could tell me too, all the tests they did never found out what was causing this situation."

Doubt about therapeutic "I always tell myself that if we had found the source, we could have solved the efficacy problem. So far all the examinations only allow us to make the observation. The sperm is not good, machiiiiiin and so on, at the beginning we thought it was an infection, we treated the infections hoping that it should come back but it never came back, we did exams we talked about varicocele, but after when we had tests... we never determined why I am having this difficulty."

Table 3. Presentation of anamnestic data and results of the interview with Mr. F.

Mr. F, originally from the Littoral Cameroon region. Banen ethnicity. 40 years old. Lives in Douala, works in road construction. Comes for a second attempt at AMP, suffers from insufficient number and mobility of sperm. First of a sibling of 7 . Fate of a very pious monogamous family of Protestant religion. Fifth year of married life without children. After taking decoctions a few times and praying without success, he dedicates himself to AMP; unfortunately, the first one tries not being successful. Mr. F cares more about his wife so his age is approaching the critical threshold for the AMP procedure. He procrastinates about submitting to an AID, a decision that is not easy to make despite desperately wanting a child for his wife.

\begin{tabular}{|c|c|c|}
\hline Theme & Descriptors & Verbatims \\
\hline \multirow[t]{3}{*}{$\begin{array}{l}\text { Data related to } \\
\text { cultural } \\
\text { constraints }\end{array}$} & $\begin{array}{l}\text { Pressure from family and } \\
\text { loved ones to continue the } \\
\text { lineage }\end{array}$ & $\begin{array}{l}\text { "People are talking behind and at home we are silent, it is much more Madam } \\
\text { listening to what we are saying." Who loves a tree that has no fruit, no one. You are } \\
\text { like a flower that adorns the court and dies afterwards, leaving no fruit. We' re still } \\
\text { bothering you." }\end{array}$ \\
\hline & $\begin{array}{l}\text { Respect for ancestral } \\
\text { values, safeguarding the } \\
\text { spiritual and social } \\
\text { heritage }\end{array}$ & $\begin{array}{l}\text { "But, you also have to leave offspring before you also die one day. You are going to } \\
\text { spend on someone's child no matter how he goes to see his parents and you are } \\
\text { going to stay like that." "It is better to have the child of your blood"someone's } \\
\text { child one always ends up going away." }\end{array}$ \\
\hline & $\begin{array}{l}\text { The practice of spiritual } \\
\text { rites and traditional } \\
\text { rituals }\end{array}$ & $\begin{array}{l}\text { "... Mom would ask us from time to time to take some potions that she gave us to } \\
\text { drink to cleanse the body"; "If my mother knows that I have a problem, she will } \\
\text { start to say that we go to the marabouts to do rituals, but if it continues like this, } \\
\text { we'll take a tour of the village to see what's wrong." }\end{array}$ \\
\hline \multirow[t]{3}{*}{$\begin{array}{l}\text { Data related to } \\
\text { the secret of the } \\
\text { AID }\end{array}$} & The secrecy's weight & $\begin{array}{l}\text { "No one is aware that we have initiated this procedure." "No one in the family knows } \\
\text { about this, well, that's the price to pay when you want the child"; "It's a grief that we } \\
\text { do alone. If not with his wife, without shouting out loud. It's very difficult to live"; } \\
\text { "It's something I ve always kept a secret, and my wife doesn't talk about it too." }\end{array}$ \\
\hline & $\begin{array}{l}\text { Failure of loyalty to } \\
\text { spouse, family and } \\
\text { community }\end{array}$ & $\begin{array}{l}\text { "...age is advancing, we have to do PMA...My wife is } 37 \text { years old...he advised us not } \\
\text { to waste time, that when age advances, the chances of success are reduced, and you } \\
\text { see soon, she will be } 40 \text { years old"; "It is her that we ask what is wrong, the neighbors, } \\
\text { the people of the family, many do not know that I have a problem, we know that she } \\
\text { is the culprit, that is why I preferred that we redo the PMA, if it can really work so } \\
\text { that we don't bother her anymore." "We will all be quiet, as well as my people." }\end{array}$ \\
\hline & $\begin{array}{l}\text { The personal } \\
\text { representation of } \\
\text { ART/AID }\end{array}$ & $\begin{array}{l}\text { If there were the means, we shouldn't have started the other the same year without } \\
\text { waiting too long, from } 2017 \text { to 2019, it's not easy, we also have to help the family"; } \\
\text { it's really too expensive, there are a lot of people who are in the same situation as } \\
\text { me but who cannot do this for lack of means"; "The ADI here at home in Africa, } \\
\text { what are you going to tell people. This is for the whites."; "When you take } \\
\text { someone's semen, whose child is that? Everyone thinks it's your child, you know } \\
\text { the truth, it hurts you even more." }\end{array}$ \\
\hline
\end{tabular}




\section{Continued}

\begin{tabular}{|c|c|c|}
\hline \multirow[t]{3}{*}{$\begin{array}{l}\text { Data related to } \\
\text { the shame of the } \\
\text { social gaze }\end{array}$} & The feeling of guilt & $\begin{array}{l}\text { "I don't know why all this is happening to me when everyone around me, my } \\
\text { brothers and sisters have children, what have I done to God?" "So that madame is } \\
\text { so happy, all that I give her now cannot replace a child." "It is difficult to hear that } \\
\text { a man does not manage to have children, it is a lot more common in women"; "All } \\
\text { I want is to give my wife a child." }\end{array}$ \\
\hline & $\begin{array}{l}\text { The feeling of loss of } \\
\text { self-esteem and the fear of } \\
\text { a possible divorce }\end{array}$ & $\begin{array}{l}\text { "... I was made to understand that euhhhhhh, my sperm count is small and that it } \\
\text { doesn't move a lot."; "Sometimes I wonder if Madame will not leave me one day, } \\
\text { the last time she cried so much"; "My in-laws, don't see me that much"; "I waited } \\
\text { for the results but unfortunately it was not positive. No one had the strength to talk } \\
\text { to the other home"; "It was very hard, I was disappointed, I was uncomfortable." }\end{array}$ \\
\hline & $\begin{array}{l}\text { The feeling of } \\
\text { incompleteness }\end{array}$ & $\begin{array}{l}\text { "No lie to you, I was euhhhhh, I was really disappointed... discouraged, very sick, } \\
\text { sad, [piafff]," It's really, really hard. "That's why I do everything I can to ensure } \\
\text { that we have our child together so that we can finally be as peaceful as other } \\
\text { people"; "It's complicated to live without children." }\end{array}$ \\
\hline
\end{tabular}

Data related to The relationship to mystical-religious witchcraft practices
"She will try to find out if it is not a spell that the wizards have cast on me or if it is not me who sought", "they will begin to accuse me of being a wizard, or that I have sold my wife's belly or I sold for myself, to get money, Yes, it is like that."

Beliefs in evil spirits and It is often said that evil spirits can prevent someone from conceiving, "I must end supernatural powers up thinking it's mystical, because I don't understand a thing at all. How is it that I am the only child of my mother among so many others to have this problem? What made my semen not work well? I wonder if that's not mystical."

The ART Process Failure in the process

"... this is the fifth year now that I can say that I have started looking for the child without success"; "My wife is already 37 years old, he told us that as the age advances the chances of success are reduced, she will soon be 40 years old, it becomes more and more worrying"; "For two years I have been looking for the money to come back and resume, it is not easy."

Doubt about the quality of "[tsuip] The other one there hmmm; you can take the blood of a bandit to your the unborn child via AID family and regret all your life."

Doubt about therapeutic "... when we take a lot of oocytes like what we removed from the lady there, there is efficacy no risk that it will end and that the next few times we will not find any more? Because of this $1 \mathrm{~m}$ really afraid. When it is said that they took 10 or 12 oocytes." "Well maybe, since you never know, you'll end up going to the traditional healer to really find out what's wrong"; "We did the exams again. Sometimes $1 \mathrm{~m}$ afraid of this situation."

F. The three tables exhaustively highlight the experience of each infertile man grappling with the problem of new reproductive technologies in Cameroon.

\section{Analysis of the HADs and the Interviews of the Three Participants}

\subsection{Analysis of HADS}

The cross-sectional analysis of the HADs shows that all three participants have almost the same scores on the two subscales with the predominance of the same items, slowing down and anxiety. All would present an anxiety depressive syndrome but would be more in the phase of depression as described by 
Kübler-Ross (1969). This positive diagnosis is justified by the absence of psychological care in the medical treatment protocol. In this phase as described by Kübler-Ross, there is the possibility of acceptance. This is the longest and often the most difficult period. According to the author, it can last for months and even extend for several years. This is the time when the imagination calms down and the patient begins to face reality. The panic begins to subside, as the emotional fog dissipates. It is the great sadness characterized by unsociability and a decrease in energy. The patient is totally immersed in his distress, fueled by feelings of guilt and constant questioning. The existence of anxiety could therefore be a brake or interference in the effectiveness of medical monitoring. It is well known that in a state of depression, whether it is masked as it seems in these three cases, or not, the body reduces the level of functioning of several of its systems to favor the vital functions.

\subsection{Interview Analysis}

The results of the interviews show that our three participants opt for integrative therapy (religious therapy, traditional therapy, medical therapy). All submit to assisted reproduction, not because they believe it is the most effective approach, but simply by testimony. After some time of searching for a solution, the idea of a supernatural component spontaneously arose among the participants. This ties in with Sow's theory Sow $(1977,1978)$ when he says that in black Africa, any difficult situation or better any disease that persists is perceived as having a supernatural aspect. Likewise, Sow (1977) explains that in Africa, the difficulties of procreation in men or women can be linked to witchcraft practices as he says, in patri-linear societies, the sorcerer uses mediators to eat the belly of his victims. All three couples have set up mechanisms of release both in relation to the rites and submission to traditional therapies, prayers and religious therapies and biomedical techniques, but especially fosterage even if the latter is not adopted by the third couple.

\subsubsection{The Defense Mechanisms Observed in the Participants}

As defense mechanisms, we find avoidance and projection in all three, denial in Mr. A, repression in Mr. C and in Mr. F. We also note the ambivalence in the three with regard to practice of the AID technique. AID's proposal plunges the three participants into suffering resulting from both cultural constraints, the preservation of secrecy, the shame of the gaze of the other in society and the mystical-religious repercussions. In the cultures of origin of those three participants, male infertility remains taboo and not having children is seen as a crime. The suffering caused by the situation is not limited to the life of the couple but extends to the whole family. Responses regarding couples' experiences with extended families were mixed. While some people reported family support, others blamed their family for their misfortune. Their sadness also had a direct impact on their sex life, as many reported reduced interests in sexual activity with their partners. These men said that having sex was both for pleasure and for procrea- 
tion, although procreation was the driving force behind sex between couples. However, with the constant failure of attempts to have children, the desire to have sex diminishes. Participants reported that a marriage without children is often seen as a curse from God, and this ties in with Sow $(1977,1978)$, when he said that the greatest misfortune that can befall a man is to die without leave offspring. So, the absence of children is a real curse. Any marital union without children is therefore seen as the victim of a sanction from the founding ancestor who has all power over the lineage; Moreover, Sow $(1977,1978)$ underlines that life, strength, fertility is articulated on the being of the founding Ancestor who thus constitutes the axis on which the existence of each person is structured.

\subsubsection{The Suffering of an Infertile African Spouse as a Result of Cultural Constraints Disrupts His ART Process}

It is clear from reading the previous results that the participants refuse to think about the possibility of sperm donation because it calls into question their virility and a loss of authority and autonomy in their relationship. They also refuse, although they ask to have a child in their home the idea of a third party present forever in their married life, because this would consist of a kind of betrayal towards his wife. In Africa and in particular in Cameroon, the man is not only the head of the couple but is considered the all-powerful, his voice is the most authorized in a household; borrowing the sperm to impregnate his partner testifies to his weakness, hence this feeling of guilt observed through the speech of our participants. The anxiety-depressive symptoms observed in them testify to their intrapsychic suffering. Some participants did not tell their loved one that they had a problem. They prefer to let their partner carry the burden. For them, they are the link in a chain and have the heavy responsibility of ensuring the continuity of this chain, which is why winning this battle would be a credo regardless of the energy, financial and time cost.

\subsubsection{The Suffering of the Infertile Cameroonian Spouse Following the Fear that the Secrecy Maintened about the IAD by the Culture Will Be Revealed Disrupting His ART Process}

This assertion finds all its relevance in view of the results obtained. This can be seen in the attitudes of the participants. All of them have kept their ART practice a secret so that no one in their family can know about it even if it fails; and it was the same with the AID proposal that even the spouse should not know. Even more, thinking of the AID, everyone is worried not only about their future and that of the future generation with a child who is not theirs, but also about the social outlook and the socio-cultural consequences related to it. The fact of imagining themselves in the more or less near future in the company of a child cut off from their blood plunges them respectively into a feeling of having violated cultural and ancestral values. These indicated that there are days when the reality of life without children seems too much to deal with, but they have found ways to deal with it through daily prayers, hope, self-confidence and true acceptance of their destiny. We understand that an adaptation strategy has been put in place 
allowing them to continue to maintain the reactions of the counter-shock, thus mobilizing the unconscious defense mechanisms that will allow them to resist until possible exhaustion. Until the announcement of this possibility of AID, everyone had hopes for a structure of ART that would allow them to move forward with a focus on the future. It must be said that it was easier to adapt to their situation, to avoid encounters with their companions, encounters likely to remind them of their lack of children.

\subsubsection{The Suffering of an Infertile Cameroonian Spouse Following the Shame of the Way Others Look at Him in Society Disrupts His ART Process}

This shows up in feelings of guilt raised in their respective speeches, feelings of loss of self-esteem and even fear of a possible divorce; especially for those whose wives had no known medical problems, or had already had a child from a previous relationship. The shame of the other's gaze in society was also felt through feelings of incompleteness, the house is empty; or full without however making the joy of the couple. Most of the participants took the children in their family to dissuade the gaze of the neighbor who might think that there are no descendants in the house.

\subsubsection{The Suffering of and Infertile Cameroonian Spouse Following the Mystical-Religious Persecutions Disrupts His ART Process}

The participants in this study all spoke of some of the mystical forces or sorcerers acting in their situation. All participants have doubts about the real cause of their problem. This is what explains a therapeutic multiverse. If they all take decoctions from traditional therapists and also go to pastors, it is because they have this feeling of being the victims of persecution. Likewise, they do not trust anyone or their close and distant surroundings. They do this to the extent that everyone is likely to be the author of their suffering, which creates potential suffering for everyone. Moreover, in Africa, as Sow (1977) pointed out so well, every family has its evil spirits and even its wizards. Likewise, the participants allude to traditional rites and customs with the aim of blocking the way for this evil spirit which would form an obstacle to their development.

\subsection{Discussion and Conclusion}

Bonnet \& Duchesne (2014) already explained that the life stories of couples in the face of medical care highlight a feeling of physical and moral exhaustion, especially for women. It must be said that the suffering of men is generally not considered by the authors who conduct studies on marital suffering linked to infertility in Africa. Bourdet-Loubère \& Pirlot (2012) already highlighted the fact that too few authors have looked at the experience of male infertility in the humanities. Despite the fact that AMP has already achieved its feats in Africa and that some couples resort to it despite financial difficulties, most prefer marabouts in the event of reproductive difficulties (Bonnet \& Duchesne, 2014). It must be said that the infertile African is more interested in knowing the cause of 
his illness; thing that can be linked to witchcraft, an evil spirit, neglected habits and customs, or even to the fate that would have been cast on it. This is all the truer as in the event of ART failure, the accusations are much more on traditional rituals which have been neglected or on an external evil hand. Likewise, in the event of a proposal for an AID, the infertile spouse shows a certain destabilization which is observed in many questions; namely: "what will I say to people?" "If my wife betrays me by blackmailing me?" "What will I say to my ancestors?", etc. These inquisitions bear witness to the fact that AID is not anchored in African mores.

Questions related to the quality (health) of the child born by ART/AID come up regularly in the speeches of our participants, who wonder about the true human dimension in children who come by this route. These questions are raised and underlined by Lazaroutou \& Golse (2006) who, considering that ART is the object of a great desire and overinvestment on the part of the parents and that the psychological consequences in the child may be inevitably linked to the development of a traumatic experience related to infertility and medical procedures. It is clear that in an African context, as emphasized by Sow $(1977,1978)$, De Rosny (1992), Mayi (2010), Nguimfack (2016) and Tsala Tsala (2009), in situations of serious or chronic illness, the African tends to go back to the source to ask for help from his ancestors. In the case of infertility, it is always depending on the results of this search for a problem so we are looking for the cause, of a collective denial of male infertility. The central problem of this research that we want to solve is the fate of the ART process of these infertile spouses; if indeed the literature on the issue echoes the importance of cultural values to which an individual belongs in the structuring of his psyche, of the meaning of his suffering in his therapeutic procedure with ART. The most poignant psychological suffering is that induced by the situation of infertility in Africa given the preponderant place of the child in the cultures of sub-Saharan Africa. In Cameroonian cultures, for example, having a child seems to be an obligation, a social constraint. Thus, all African families, whether modernized or not, have this supernatural inclination towards negative life events (Nguimfack, 2016; Tsala Tsala, 2009). Thus, the symptomatology of anxiety and depressive states noted after the HADs scale; pressure from the family to continue the lineage; respect for ancestral values; the practice of rites and rituals; the weight of secrecy associated with AMP; failure of loyalty to spouse, family and community; feelings of guilt; feelings of low self-esteem and fear of possible divorce; the relationship to witchcraft, the belief in evil spirits could have a strong impact on the AMP journey of the infertile Cameroonian spouse. All these cultural factors will thus generate the failures, the abandonment of the procedure, animated by the doubt on the quality of the unborn child via IAD, the doubt on the efficiency of the medical profession and even of the therapeutic efficacy observed in patients. the infertile spouse struggling with ART. So, for the infertile African, to submit to artificial insemination with the sperm of a donor would create a kind of rupture, 
first between him and the higher sub-universe of the macrocosmos, that is to say, God, the Founding Ancestor and the spirits of the elected deceased; then between him and the sub-universe of the mesocosmos, made up of wandering spirits, genies and the place of nocturnal operations of sorcerers; and finally, between him and the sub-universe of the microcosm, that is to say, the village, the society. According to Sow (1977), the sub-universe of the mesocosmos is the domain par excellence of African culture, the place where this culture locates latent and apparent conflicts, the place of social movement. In this case, we can understand the suffering of the infertile Cameroonian spouse who imagines the secret he will carry for having borrowed the sperm of a donor in order to have a child. So, whether it is vis-à-vis the donor, the spouse, family members, relatives or the unborn child, secrecy, whatever its content, generates suffering in the wearer. Thus, we join Boden (2013) in saying that the necessity for psychological support to be offered at the point of ending treatment is crucial.

\section{Conflicts of Interest}

The authors declare no conflicts of interest regarding the publication of this paper.

\section{References}

Aoudou, C. M. (2009). Acceptabilité socioculturelle de la politique etdes programme de population au Cameroun. Une analyse anthropologique de la fécondité et de la mortalité. Thèse de Doctorat, Université de Yaoundé 1.

Boden, J. (2013). The Ending of Treatment: The Ending of Hope. Human Fertility, 16, 22-25. https://doi.org/10.3109/14647273.2013.777802

Bonnet, D. (2014). Adopter un enfant dans le contexte de la Procréation médicalement assistée en Afrique subsaharienne. Cahiers d'études africaines, 215, 769-786.

Bonnet, D., \& Duchesne, V. (2016). Procréation médicale et mondialisation: Expériences africaines (250 p.). L'Harmattan.

Boszormenyi-Nagy, I., \& Spark, G. (1973). Invisible Loyalties: Reciprocity in Intergenerational Family Therapy. Harper\& Row.

Bourdet-Loubère, S., \& Pirlot, G. (2012). Le vécu psychologique d'hommes infertiles: Apports du repérage de l'aménagement défensif. L'information psychiatrique, 88, 721-726. https://doi.org/10.3917/inpsy.8809.0721

De Rosny, E (1992). Afrique des guérisons. Karthala Editions.

Delaisi de Parseval, G. (2009). Secret des origines/inceste/procréation médicalement assistée avec des gamètes anonymes: Ne pas l'épouser/Essai. Anthropologie et Sociétés, 33, 157-169. https://doi.org/10.7202/037818ar

Durif-Varembont, J., Guérin, J., Mercader, P., Dumet, N., Perret, Z., \& de Souza, A. (2018). La dynamique familiale des couples en attente de procréation par IAD. Dialogue, 219, 77-90. https://doi.org/10.3917/dia.219.0077

Faye, S. L. (2011). Quand les tradithérapeutes oust-africains soignent l'infertilité conjugale à Dakar (Sénégal): Recompositions et dynamiques entrepreneuriales. Anthropologie \& Santé, 3. https://doi.org/10.4000/anthropologiesante.755

Frith, L. (2001). Gamete Donation and Anonymity: The Ethical and Legal Debate. Human Reproduction, 16, 818-824. https://doi.org/10.1093/humrep/16.5.818 
Howe, S., Zulu, J. M., Boivin, J., \& Gerrits, T. (2020). The Social and Cultural Meanings of Infertility for Men and Women in Zambia: Legacy, Family and Divine Intervention. Facts, Views \& Vision in ObGyn, 12, 185-193.

Hurault, J. (1987). Un ouvrage méconnu: Infécondité en Afrique Noire d'Anne RetelLaurentin. Cahiers d Etudes Africaines, 105-106, 177-185. https://doi.org/10.3406/cea.1987.3199

Jouannet, P. (2013). Procréer grâce à un don de sperme: accueillir et transmettre sans gêne. La Revue des droits de l'homme, 3, 103-112. https://doi.org/10.4000/revdh.200

Kaufman, J.-C. (2014). Le choix du conjoint. In J.-C. Kaufmann (Ed.), Sociologie du couple (pp. 5-30). Presses Universitaires de France.

Kübler-Ross, E. (1969). On Death and Dying. Macmillan Publishing Co., Inc.

Lazaroutou, H., \& Golse, B. (2006). Du désir à l'acte: Les enfants de la procréation médicalement assistée (PMA). La psychiatrie de l'enfant, 49, 573-599. https://doi.org/10.3917/psye.492.0573

Mayi, M. B. (2010). Psychopathologie et Tradithérapie Africaine: Perspective actuelle. Dyanoïa.

Meijers, T. (2020). The Value in Procreation: A Pro-tanto Case for a Limited and Conditional Right to Procreate. The Journal of Value Inquiry, 54, 627-647. https://doi.org/10.1007/s10790-020-09734-5

Ngon, C. (2018). Tradition et légendes: au cœur des rites et traditions du peuple Maka. https://www.auletch.com/tradition-et-legendes-au-coeur-des-rites-et-traditions-du-pe uple-maka/

Nguekeu, M. R. (2015). Vécu des liens familiaux et états dépressifs chez la femme Bamiléké infertile: une étude de cas. Thèse de master, l'Université de Yaoundé 1.

Nguimfack, L. (2016). Psychothérapie des familles camerounaises confrontées à la sorcellerie, intervention systémique auprès de la famille d'un enfant délinquant. Thérapie familiale, 3, 293-305. https://doi.org/10.3917/tf.163.0293

Organisation Mondiale de la Santé (WHO) (2020). Infertilité. https://www.who.int/fr/news-room/fact-sheets/detail/infertility

Sow, I. (1977). Psychiatrie dynamique Africaine. Payot.

Sow, I. (1978). Les structures anthropologiques de la folie en Afrique Noire. Payot.

Squires, C., Jouannet, P., Wolf, J.-P. Cabrol, D., \& Kuntsmann, J.-M. (2008). Psychopathologie et procréation médicalement assistée: Comment les couples infertiles élaborentils la demande d'enfant? Devenir, 20, 135-149. https://doi.org/10.3917/dev.082.0135

Tabong, P. T., \& Adongo, P. B. (2013). Understanding the Social Meaning of Infertility and Childbearing: A Qualitative Study of the Perception of Childbearing and Childlessness in Northern Ghana. PLoS ONE, 8, e54429. https://doi.org/10.1371/journal.pone.0054429

Théry, I., \& Leroyer, A.-M. (2014). Filiations, origines, parentalité: Le droit face aux nouvelles valeurs de responsabilité générationnelle. Odile Jacob.

Tiu, M. M. H., Hong, J. Y. F., Cheng, V. S., Kam, C. Y. C., \& Ng, B. T. Y. (2018). Lived experience of infertility among Hong Kong Chinese women. International Journal of Qualitative Studies on Health and Well-Being, 13, Article No. 1554023. https://doi.org/10.1080/17482631.2018.1554023

Tsala Tsala, J.-P. (2009). Famille Africaine en thérapie. Clinique de la famille camerounaise. L'Harmattan.

Yana, S. D. (1988). A la recherche des modèles culturels de la famille et de la fécondité au Cameroun. L'Harmattan. 